ISSN 1112-9867

Available online at

http://www.jfas.info

\title{
STUDY OF THE PROPOLIS EXTRACT AS A CORROSION INHIBITOR OF COPPER ALLOY IN ETHYLENE GLYCOL / WATER 0.1 M NaCI
}

\author{
H. Hachelef* ${ }^{1}$, A. Benmoussat ${ }^{1}$, A. Khelifa ${ }^{2}$, M. Meziane ${ }^{3}$ \\ ${ }^{1}$ Materials and Corrosion Equip of LAEPO Research Laboratory Abobeker Belkaid \\ University of Tlemcen BP 230, Tlemcen 13000 Algeria \\ ${ }^{2}$ Research laboratory of processes Genius, Department of Industrial Chemistry, Faculty of \\ Technology, Saâd Dahlab University of Blida, BP 270, 09000, Blida, Algeria \\ ${ }^{3}$ Laboratory of fundamental and applied physics Faculty of Technology, Saâd Dahlab \\ University of Blida, BP 270, 09000, Blida, Algeria
}

Received: 26 September 2016 / Accepted: 15 April 2017 / Published online: 01 May 2017

\begin{abstract}
The effect of propolis extract as a corrosion inhibitor of copper alloy in ethylene glycol / water $0.1 \mathrm{M} \mathrm{NaCl}$ solution was studied by electrochemical measurements. The Tafel polarization curves showed that the propolis extract at different concentration acts as mixed inhibitor, and the maximum value of the inhibitory efficacy is $73.28 \%$ at optimum concentration of $1.25 \mathrm{~g} / \mathrm{L}$ of propolis extract. The activation parameters reveal that the inhibitor molecules on copper surface are absorbed by physisorption and obey Langmuir isotherm adsorption. These results were supplemented by IR Spectroscopy, Scanning electron microscopy (SEM) and EDX spectrum of chemical composition. The metal solution interface is simulated as a physical model by using Electrochemical Impedance Spectroscopy (EIS).
\end{abstract}

Keywords: Copper Alloy, Propolis extract, ethylene glycol; Corrosion inhibition; Adsorption, Electrochemical impedance Spectroscopy (EIS).

Author Correspondence, e-mail: hachelefhakima@yahoo.fr doi: http://dx.doi.org/10.4314/jfas.v9i2.3 


\section{INTRODUCTION}

Water and ethylene glycol-water solutions are fluids commonly used in cooling systems. Although the fluids are the essential component of heat transfer applications, they can also cause corrosion within the systems. Studies show that uninhibited ethylene glycol degrades in five organic components (glycolic, glyoxylic, formic, carbonic acid and oxalic acid) in the presence of heat, oxygen and metals that are commonly found in cooling systems, such as copper and aluminum [1-6]. When copper is corroded, it is often degraded by general corrosion. General corrosion will often attack the copper exposed to oxygen or fluids with high sulfur content or salts dissolved in the fluid, such as chloride ions.

The corrosion of copper can be inhibited by a wide range of substances which may be synthetic or natural inhibitors, such as the biomaterials [1,4,5], Synthetic compounds containing multiple bonds and hetero atoms which are effective inhibitors, but at the same time the processing time, cost and their toxic nature have compelled the researchers to look for eco-friendly, nontoxic and low cost inhibitors for the corrosion protection of metals. Many corrosion prevention works have been carried out using extracts of various plants as corrosion inhibitors [6-24]. The use of plants extracts has been found to be viable alternative. The bioactive compounds in the plant extract are as effective as synthetic inhibitors [20-24]. These bioactive compounds act as inhibitors in ethylene glycol / water $0,1 \mathrm{M} \mathrm{NaCl}$. They also interact with metals and affect the corrosion reaction in a number of ways, some of which may occur simultaneously. Propolis is a resinous substance prepared by honeybees from buds, leaves and exudates of trees and plants mixed with pollen, wax and enzymes secreted from the bees $[5,21]$. Some important characteristics have been reported concerning this substance, such as antimicrobial and antioxidant effects, anesthetic properties and others, it found that the propolis extracts represent an important functional product, rich in flavonoids and polyphones [8-12]. The used raw propolis have been obtained in harvest month of April from the region of Bordj El - Menaiel in septembre 2014, copper alloy behavior in ethylene glycol (30\%)-water(70\%) solution $0,1 \mathrm{M} \mathrm{NaCl}$ with and without propolis extract as corrosion inhibitors motivate our research. The purpose of the present work is to examine the inhibition effect of propolis extract on copper corrosion in ethylene glycol (30\%)/ water 
(70\%) solution $0,1 \mathrm{M} \mathrm{NaCl}$. The inhibitory efficiency of this alloy immersed in this solution will be evaluated using various electrochemical techniques namely, the potentiodynamic polarisation curves and electrochemical impedance spectroscopy (EIS). These results were supplemented by IR Spectroscopy, Scanning electron microscopy (SEM) coupled with EDX.

\section{MATERIALS AND METHODS}

2.1. Materials: A copper alloy of Rectangular dimension $1 \mathrm{~cm}^{2}$ is used as a sample electrode. The chemical compositions of the alloy used are shown below in Table1 determined by spectrometry kind "SPECTROLAB".

Table 1. Chemical composition of copper alloy used in Wt. \%

\begin{tabular}{l|lllllllll}
\hline $\boldsymbol{C u}$ & $\mathrm{Mn}$ & $\mathrm{Si}$ & $\mathrm{Mg}$ & $\mathrm{Fe}$ & $\mathrm{Co}$ & $\mathrm{Au}$ & $\mathrm{Se}$ & $\mathrm{Sb}$ & $\mathrm{Zn}$ \\
\hline $\mathbf{7 0 . 7}$ & 0.0005 & 0.0005 & 0.0002 & 0.014 & 0.016 & 0.0043 & 0.019 & 0.015 & 29.19 \\
\hline
\end{tabular}

The cutting process was chosen as it does not alter the microstructure and corrosion test at the coupon surface due to its low heat input and the absence of mechanical damage by avoiding the thermically affected zones. Pre-treatment of copper sample surfaces was carried out by grinding with emery paper of 600- 1200 grit, rinsing with bidistilled water, and ultrasonic degreasing in acetone and dried at room temperature .

\subsection{Solution preparation}

Sample of propolis extract has been obtained in harvest month of April from the region of Bordj El Menaiel in Algeria. The extract was prepared by dissolving 5g of propolis in $100 \mathrm{ml}$ of ethylene glycol. This extract was used to study the corrosion inhibition in ethylene glycol $(30 \%)$ / water $(70 \%) 0.1 \mathrm{M} \mathrm{NaCl}$. The solution tests are freshly prepared before each experiment. Experiments were carried out in triplicate to ensure the reproducibility.

\subsection{Electrochemical tests}

The electrochemical study was carried out using a potentiostat Autolab brand piloted by Nova 1.7 software, connected to a cell with three electrode thermostats and double wall (Tacussel Standard CEC/TH). A saturated calomel electrode (SCE) and platinum electrode have been used as reference and auxiliary electrodes, respectively. The surface area exposed to the 
electrolyte is $1 \mathrm{Cm}^{2}$. The working electrode was immersed in the testing solution for $1 / 2 \mathrm{~h}$ to reach a quasi-stationary value of the open circuit potential prior to the measurements. Tafel polarization curves were obtained by changing the electrode potential automatically from - 150 to $+150 \mathrm{mV}$ (vs. SCE) at a scan rate of $1 \mathrm{mV}^{-1}{ }^{-1}$. The electrochemical impedance spectroscopy (EIS) measurements are carried out with the electrochemical system (Tacussel), which included a digital potentiostat model Autolab 1.7 computer at Ecorr after immersion in solution without bubbling. After the determination of steady-state current at a corrosion potential, sine wave voltage $(10 \mathrm{mV})$ peak to peak, at frequencies between $100 \mathrm{kHz}$ and 10 $\mathrm{mHz}$ are superimposed on the rest potential. Computer programs automatically controlled the measurements performed at rest potentials after half an hour of exposure at $298 \mathrm{~K}$. The impedance diagrams are given in the Nyquist, Bode and plot phase representation. Experiments are repeated three times to ensure the reproducibility. The corrosion inhibition efficiency (E) by potentiodynamic polarization was calculated from the value of icorr by using the formula (1) [24-26].

$$
E(\%)=\frac{i_{c o r r}^{0}-i_{\text {corr }}}{i_{c o r r}^{0}} \times 100
$$

$i_{\text {corr }}^{0}$ and $i_{\text {corr }}$ are the corrosion current in the absence and presence of the inhibitor, respectively.

The inhibition efficiency by electrochemical impedance was calculated using the equation [25].

$$
E(\%)=\frac{R_{p}-R_{p}^{0}}{R_{p}} \times 100
$$

$R_{p}^{0}$ and $R_{p}$ are the polarization resistance in the absence and presence of the inhibitor, respectively.

\subsection{Temperature studies}

The Tafel polarization curves and the electrochemical impedance spectroscopy (EIS) measurements analysis were performed at different temperatures of 298,313,353, K, using a thermostat to study the inhibition efficiency of the extract. This provided details on the nature of the adsorption and activation energies. The activation energy ( $E a)$ of the inhibitor was 
calculated by a graphical method, plotting $\log (C)$ versus $1000 / T\left(\mathrm{~K}^{-1}\right)$ for the temperatures of $298,313,353, \mathrm{~K}$ in ethylene glycol $(30 \%$ ) / water (70\%) $0,1 \mathrm{M} \mathrm{Na} \mathrm{Cl}$, both with and without the inhibitor. At all extract concentrations Ea was calculated using the formula:

$$
\begin{aligned}
& E a=-2.303 \times 8.314 \times \text { Slope }(J) \\
& K=\frac{\theta}{c(1-\theta)}
\end{aligned}
$$

where $\theta$ is the surface coverage of the inhibitor, $C$ is the concentration of the inhibitor in $\mathrm{g} / \mathrm{l}$, $K$ is the equilibrium constant, and $T$ is the temperature.

\subsection{Technical analysis}

The copper specimen was characterized with the aid of FEI Quanta 650 FEG scanning electron microscope (SEM) (magnification range from 5-1,000,000x) ( High-vacuum (HV) mode (pressure range $10^{-2}-10^{-4} \mathrm{~Pa}$ ). The SEM images were taken at the accelerating voltage of $10 \mathrm{kV}$ .Test specimens of $1 \times 1 \mathrm{~cm}^{2}$ in size were immersed in $100 \mathrm{~mL}$ of ethylene glycol (30\%)water $(70 \%) 0.1 \mathrm{MNaCl}$ containing $1,25 \mathrm{~g} / \mathrm{L}$ of propolis extract for $24 \mathrm{~h}$ at $298 \pm 2 \mathrm{~K}$. After washing, the test specimens were dried and their morphologies were examined. The study solution containing $1,25 \mathrm{~g} / \mathrm{L}$ of propolis extract before and after the 24 hours of immersion was analyzed with IR Spectroscopy and UV-visible.

\section{RESULT AND DISCUSSION}

\subsection{Electrochemical method}

\subsubsection{Effect of inhibitor concentration:}

\subsubsection{Open circuit potential (OCP) measurements}




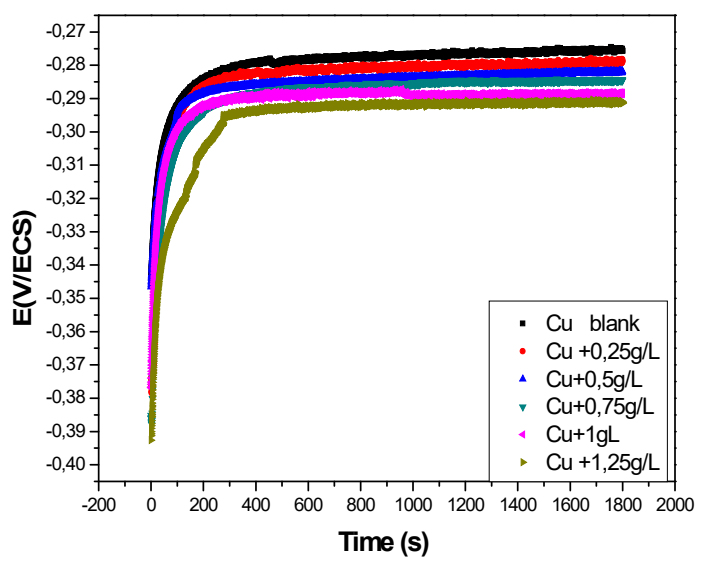

Fig.1. OCP curves for copper alloy in ethylene glycol (30\%) / water (70\%) $0.1 \mathrm{M} \mathrm{NaCl}$ at different concentrations of propolis extract

Figure.1 shows the evolution of the open circuit potential (OCP) with time of the copper alloy at a temperature of $25{ }^{\circ} \mathrm{C}$ and at various concentrations of the propolis extract in ethylene glycol (30\%) /water (70\%) solution $0.1 \mathrm{M} \mathrm{NaCl}$. Inspection of these curves shows that between 0-200 seconds there is an increase in potential values for different concentrations, above 200 seconds we notice the appearance of a bearing with a displacement of potential to negative values of $-0,28 \mathrm{~V}$ to $-0,291 / \mathrm{SCE}$ for a concentration $1,25 \mathrm{~g} / \mathrm{L}$. This bearing is explained by a passivation phenomenon due to the formation of a copper oxide layer

\subsubsection{Potentio-dynamic curves}

The study of the influence of the concentration of $0.25,0.5,0.75,1$ and / $\mathrm{L}$ and $1.25 \mathrm{~g} / \mathrm{L}$ of the propolis extract of ethylene glycol (30\%) / water (70\%) solution $0,1 \mathrm{M} \mathrm{NaCl}$ on the curves polarization of copper alloy at $298 \mathrm{~K}$ is shown in the following figure (2).

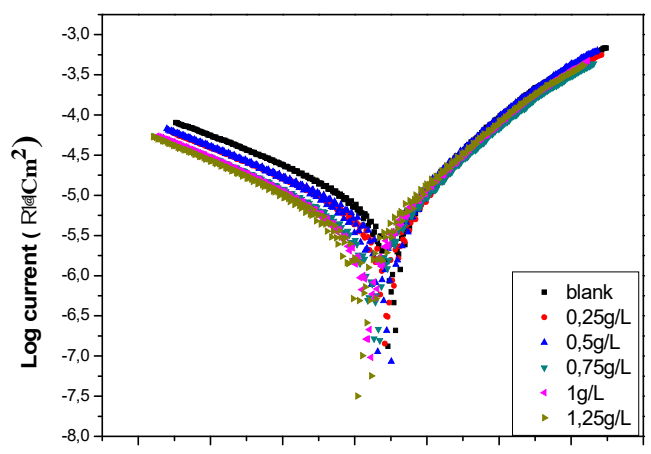

Fig.2. Potentiodynamic curves for copper alloy in ethylene glycol (30\%) - water (70\%)

$0.1 \mathrm{M} \mathrm{NaCl}$ at different concentration of propolis extract 
lowering of the cathodic corrosion current density. The electrochemical such as corrosion potential $(E$ corr $)$, corrosion current density $\left(i_{\text {corr }}\right)$, cathodic Tafel slope $(b c)$, anodic Tafel slope (ba) and inhibition efficiency (E \%) are calculated and given in Table1.

Table 1. Potentiodynamic polarization parameters for the corrosion of copper alloy in ethylene glycol / water $1 \mathrm{M} \mathrm{NaCl}$ containing different concentrations of propolis extract

\begin{tabular}{c|lllllcc}
\hline Concentration $(\mathbf{g} / \mathbf{l})$ & $\mathbf{b a}(\mathbf{V} / \mathbf{d e c})$ & $\mathbf{b c}(\mathbf{V} / \mathbf{d e c})$ & $\mathbf{E c o r r}(\mathbf{V})$ & jcorr $\left(\mathbf{A} / \mathbf{c m}^{2}\right)$ & $\mathbf{R p}(\quad)$ & $(\mathbf{E})(\boldsymbol{\%})$ & $(\theta)$ \\
\hline blank & 0,2448 & 0,090529 & $-0,27591$ & $1,6368 \cdot 10^{-5}$ & 1753,5 & $/$ & $/$ \\
$\mathbf{0 , 2 5}$ & 0,20336 & 0,08445 & $-0,27707$ & $9,8412.10^{-6}$ & 2633,3 & 39,87 & 0,3987 \\
$\mathbf{0 , 5}$ & 0,16485 & 0,078365 & $-0,27957$ & $6,5362.10^{-6}$ & 3529,2 & 60,06 & 0,6006 \\
$\mathbf{0 , 7 5}$ & 0,16489 & 0,080766 & $-0,28543$ & $6,1701.10^{-6}$ & 3815,8 & 62,304 & 0,62304 \\
$\mathbf{1}$ & 0,15629 & 0,080281 & $-0,29012$ & $6,0788.10^{-6}$ & 3789,2 & 62,86 & 0,6286 \\
$\mathbf{1 , 2 5}$ & 0,13314 & 0,075061 & $-0,29685$ & $4,3733.10^{-6}$ & 4766,7 & 73,283 & 0,73283 \\
\hline
\end{tabular}

The analysis of these values shows an increase in the inhibitory efficacy in a very remarkable manner. The increase of $39,87 \%$ shifts to a maximum value of $73,283 \%$ at a concentration of $1,25 \mathrm{~g} / \mathrm{L}$ extract. This increase can be explained by a phenomenon of absorption of molecules in the propolis extract on the copper alloy surface, which reduces the corrosive activity. The plot of the efficiency $(\mathrm{E})$ depending on the concentration and the trace $\mathrm{C} / \theta$ depending on the concentration of the extract will allow us to approach absorption model product at the metal / solution interface.

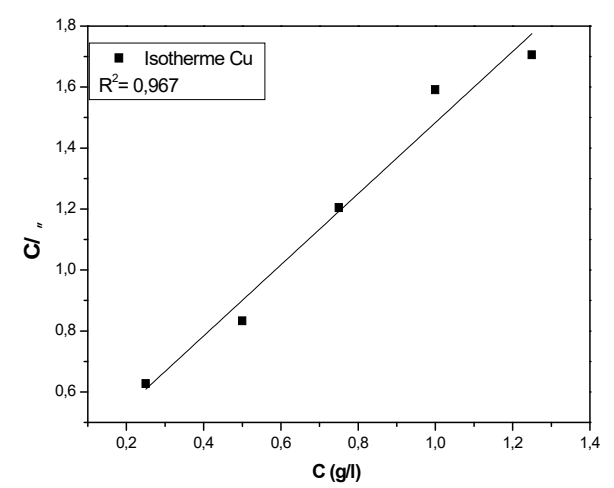

Fig.3. Langmuir isotherm for copper alloy immersed in an ethylene glycol / water solution

\section{$0.1 \mathrm{M} \mathrm{NaCl}$}


This plot gives a straight line with a correlation coefficient of 0,967 indicating that the adsorption of the propolis extract to the copper alloy surface follows the Langmuir isotherm. The inhibitory action phenomenon of propolis extract is based on a mechanism of action by simple adsorption to the metal surface, thus blocking the active sites and thus reducing the corrosion current density.

\subsubsection{Electrochemical impedance spectroscopy}

Figure .4 Represents the Nyquist, Bode, Phase angle diagrams of the copper alloy at different concentrations of propolis extract at $298 \mathrm{~K}$. These diagrams were obtained after 30 minutes of immersion in open circuit.
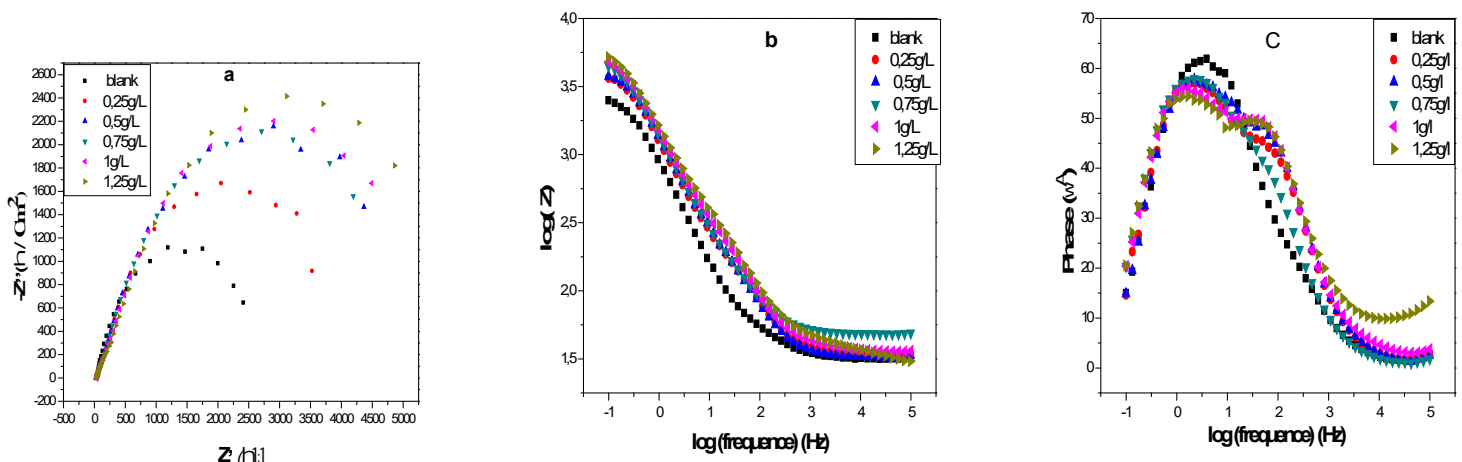

Fig.4. (a) Nyquist plots , (b) Bode (plot) (c) phase angle for copper alloy immersed in an ethylene glycol / water solution $0.1 \mathrm{M} \mathrm{NaCl}$ at different concentrations of inhibitor

It is apparent from these plots that the Nyquist diagram response of copper alloy in anuninhibited solution has significantly changed after the addition of propolis extract in the electrolytic solution. This indicates that the Nyquist diagram of inhibited substrate increase with increasing inhibitor concentration and consequently the inhibition efficiency increases. The Nyquist plot has the shape of a quarter of a lemniscates which is a phenomenon of diffusion justified by the straight line of Warburg at high frequencies and the appearance of a constant phase element at bases frequency related to the capacity of the double layer. The equivalent circuit reactions ox / red produced at the metal interface solution is shown in Figure (5) which follows: 


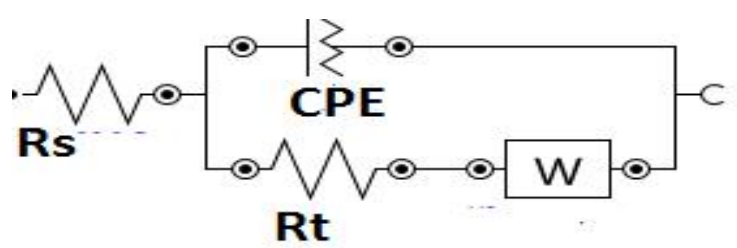

Fig.5. Electrochemical equivalent circuit corresponding to the metal / solution interface

The electrochemical equivalent circuit includes the charge transfer (RT) and Warburg impedance which indicates the presence of the diffusion phenomenon of the $\mathrm{Cu}^{2+}$ cation to the solution in parallel with the phase constant element (CPE) which results from the formation of a layer of oxide on the surface of the copper alloy.

Table 2. Impedance parameters for copper alloy in the absence and presence of the inhibitor

\begin{tabular}{|c|c|c|c|c|c|c|}
\hline Concentration $(g / L)$ & CPE.YO (F) & $\operatorname{Rp} . R($ ) & Rs.R( ) & CPE.N & $E(\%)$ & $(\theta)$ \\
\hline blank & 0,00017679 & 2692,5 & 53,904 & 0,99795 & l & l \\
\hline 0,25 & 0,00016303 & 3938,7 & 113,85 & 0,99777 & 31,63 & 0,3163 \\
\hline 0,5 & 0,00014201 & 4001,6 & 135,06 & 0,99802 & 32,71 & 0,3271 \\
\hline $\mathbf{0 , 7 5}$ & 0,00013135 & 5183,6 & 109,78 & 0,99742 & 48,05 & 0,4805 \\
\hline 1 & 0,00012209 & 5606 & 106,4 & 0,99716 & 51,97 & 0,5197 \\
\hline 1,25 & 0,00011695 & 6026,9 & 174,74 & 0,99731 & 55,32 & 0,5532 \\
\hline
\end{tabular}

Inspection of data in table 1 shows a decrease of (CPE) with increasing extract concentration. This decrease may be attributed to the formation of a protective layer on the electrode surface; and the increase in the transfer resistance charge can be justified by the blocking of corrosive sites by the propolis extract. The value of 'n' which is not equal to 1 is due to the surface heterogeneity.

\subsubsection{Effect of temperature}

Potentiodynamic curves have been carried out at different temperatures (298, 313,353 K).

The electrochemical parameters obtained for polarization curves for each concentration to different temperatures are grouped in the following table: 
Table 3. Potentiodynamic parameters and inhibitory efficiency for each concentration of the propolis extract at different temperatures 298,313 and $353 \mathrm{~K}$

\begin{tabular}{|c|c|c|c|c|c|c|}
\hline $\begin{array}{c}\text { Température } \\
(\mathrm{K})\end{array}$ & $\begin{array}{c}\text { Concentration } \\
(\mathrm{g} / \mathrm{L})\end{array}$ & $\operatorname{Ecorr}(V)$ & jcorr $\left(A / c^{2}\right)$ & $\boldsymbol{R p}(\quad)$ & (E) $\%$ & $(\theta)$ \\
\hline \multirow{6}{*}{298} & blank & -0.27591 & $1.6368 .10^{-5}$ & 1753.5 & 1 & 1 \\
\hline & 0,25 & -0.27707 & $9.8412 .10^{-6}$ & 2633.3 & 39,87 & 0,3987 \\
\hline & 0,5 & -0.27957 & $6.536210^{-6}$ & 3529.2 & 60,06 & 0,6006 \\
\hline & 0,75 & -0.28543 & $6.170110^{-6}$ & 3815.8 & 62,304 & 0,62304 \\
\hline & 1 & -0.29012 & $6.078810^{-6}$ & 3789.2 & 62,86 & 0,6286 \\
\hline & 1,25 & -0.29685 & $4.373310^{-6}$ & 4766.7 & 73,283 & 0,73283 \\
\hline \multirow{6}{*}{313} & blank & -0.26424 & $2,34.10^{-05}$ & 1269.7 & I & I \\
\hline & 0,25 & -0.27255 & $1,03.10^{-05}$ & 2250.7 & 55,9352441 & 0,55935244 \\
\hline & 0,5 & -0.27918 & $8,5510^{-6}$ & 2657.4 & 63,4624749 & 0,63462475 \\
\hline & 0,75 & -0.2732 & $6,1910^{-6}$ & 2950.7 & 73,5649908 & 0,73564991 \\
\hline & 1 & -0.27715 & $5,9910^{-6}$ & 3487.8 & 74,3932339 & 0,74393234 \\
\hline & 1,25 & -0.2772 & $4,6810^{-6}$ & 3517.9 & 79,9940199 & 0,7999402 \\
\hline \multirow{6}{*}{353} & blank & -0.27874 & $4,66.10^{-05}$ & 735.4 & I & I \\
\hline & 0,25 & -0.27691 & $3,93.10^{-05}$ & 831.89 & 15,7647513 & 0,15764751 \\
\hline & 0,5 & -0.28066 & $3,08.10^{-05}$ & 924.7 & 29,928 & 0,299282 \\
\hline & 0,75 & -0.25434 & $2,76.10^{-05}$ & 882.18 & 40,8146194 & 0,40814619 \\
\hline & 1 & -0.27119 & $2,33.10^{-05}$ & 1100.1 & 49,9688995 & 0,49968899 \\
\hline & 1,25 & -0.285 & $1,82.10^{-05}$ & 1384.5 & 60,9506038 & 0,60950604 \\
\hline
\end{tabular}

Inspection of the results of this table allowed us to observe that, for each concentration is an increase in corrosion rates with the increase in temperature; followed by a remarkable increase in the recovery rate of surface Hoar and Holiday [28] attributed to the increase of the inhibitory efficacy to high temperatures, to a high activation energy during adsorption and high diffusion rate of inhibitory molecules. Singh et al [29] have justified the increasing of the inhibitory efficacy with increasing temperature by the appearance of some chemical changes in the inhibitory molecule which causes an increase in the levels of electronic densities center adsorption of the molecule, and therefore an increase of recovery rate of the surface. Tatati and Gandhi [30] attributed the increase in efficiency to the temperature increase of the area of the metal surface covered by the inhibitor molecules. Fig .6 shows the effect of temperature on the 
corrosion current density for each concentration of inhibitor.
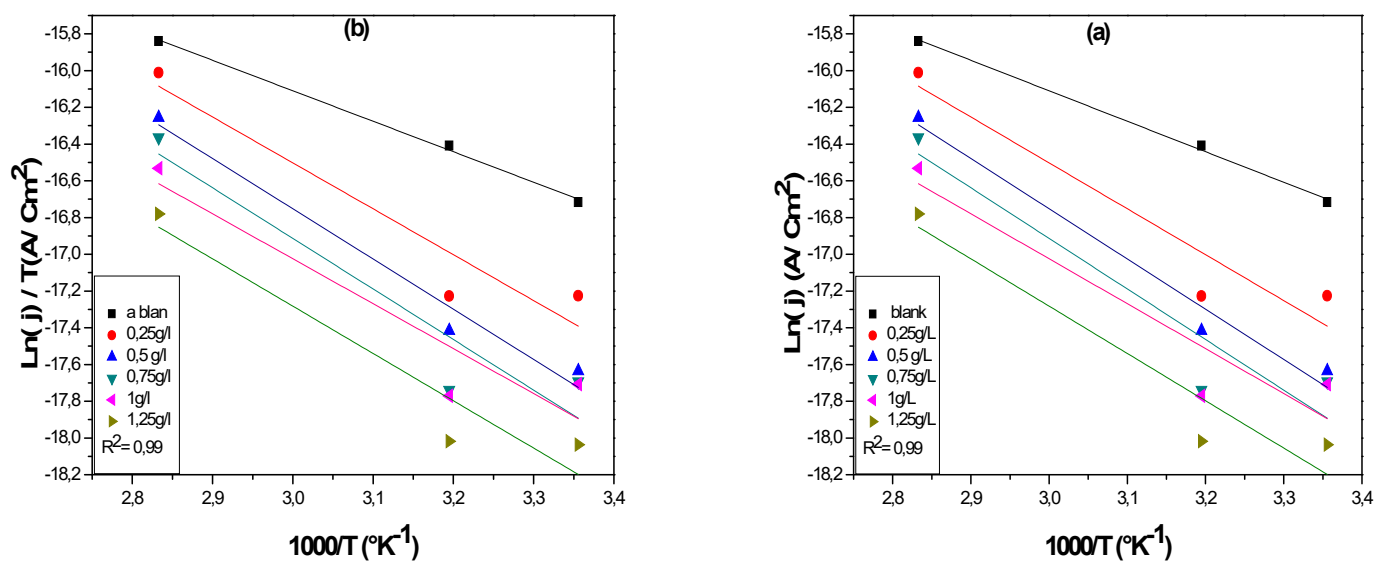

Fig.6. (a) Logarithm plot of the corrosion current densities (b) Arrhenius plots for the copper alloy immersed in an ethylene glycol (30\%) / water (70\%) solution $0,1 \mathrm{M} \mathrm{NaCl}$ at various concentrations of the propolis extract

a) Thermodynamic activation parameters:

The dependence of corrosion current densities at temperature can be expressed by Arrhenius equation and transition state equation $[26,30]$ :

$$
\ln i_{\text {corr }}=\frac{-E a}{R T}+\ln K
$$

where $i_{c o r r}$ is the density corrosion current $\left(\mathrm{A} . \mathrm{cm}^{-2}\right) ; \mathrm{K}$ a constant (pre-exponential factor), $\mathrm{Ea}$, the activation energy $\left(\mathrm{kJ} \mathrm{mol}^{-1}\right) ; \mathrm{R}$ is the gas constant $\left(\mathrm{J} \cdot \mathrm{mol}^{-1} \cdot \mathrm{K}^{-1}\right)$ and $\mathrm{T}$ the temperature $(\mathrm{K})$.

$$
i_{\text {corr }}=\frac{R T}{N h} \exp \frac{\Delta S_{a}^{0}}{R} \exp \frac{-\Delta H_{a}^{0}}{R T}
$$

The relationship between $\ln (\mathrm{j}, \mathrm{T})$ and $1 / \mathrm{T}$ is shown in fig.6 (b). The Straight lines are obtained with a slope $\left(\Delta \mathrm{H}^{0}{ }_{\mathrm{a}} / \mathrm{R}\right)$ and an intercept of $\left.\log [\mathrm{R} / \mathrm{Nh})+\left(\Delta \mathrm{S}_{\mathrm{a}}^{0} \mathrm{l}\right)\right]$, from which the value of $\Delta \mathrm{H}^{0}$ and $\Delta \mathrm{S}^{0}{ }_{\mathrm{a}}$ were calculated and presented in table.4: 
Table 4. Thermodynamic activation parameters of copper alloy in ethylene glycol / Water (30/70) $0,1 \mathrm{M} \mathrm{NaCl}$ in absence and presence of different concentrations of inhibitor

\begin{tabular}{c|ccc}
\hline Inhibitor concentration & $\boldsymbol{E}_{\boldsymbol{a}}(\mathbf{j} / \mathbf{m o l})$ & $\Delta \boldsymbol{H}^{\mathbf{0}}(\mathbf{j} / \mathbf{m o l})$ & $\Delta \boldsymbol{S}_{\boldsymbol{~}}{ }_{(j}(\mathbf{j} / \mathbf{m o l} . \mathbf{K})$ \\
\hline blank & 16518 & 13802,88 & $-290,2848$ \\
$\mathbf{0 , 2 5}$ & 23485,68 & 20783,36 & $-272,62144$ \\
$\mathbf{0 , 5}$ & 25459,2 & 22746,88 & $-268,81088$ \\
$\mathbf{0 , 7 5}$ & 25608.96 & 22904,96 & $-269,67616$ \\
$\mathbf{1}$ & 23054,72 & 20350,72 & $-279,9264$ \\
$\mathbf{1 , 2 5}$ & 24135.488 & 21424 & $-277,18912$ \\
\hline
\end{tabular}

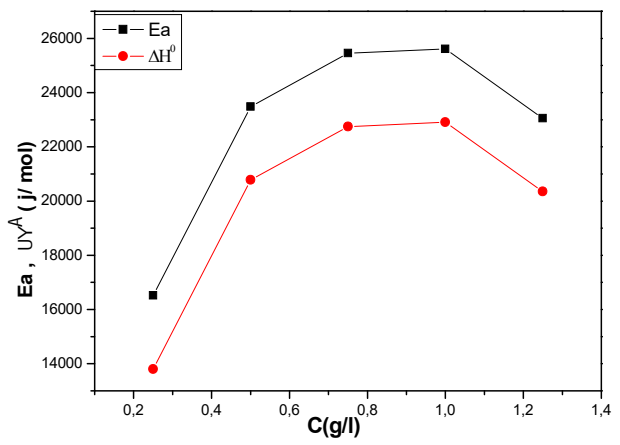

Fig .7. Curve of the variation of the activation energy and the activation enthalpy for the copper alloy in an ethylene glycol / water solution $0,1 \mathrm{M} \mathrm{NaCl}$ at various concentrations of the propolis extract

Inspection of fig.7 indicated that the value of activation energy and enthalpy of activation varied in the same way, this result verified the thermodynamic relation between $\mathrm{E}_{\mathrm{a}}$ and $\Delta \mathrm{H}$ $[27,31]$.

b) Thermodynamic adsorption parameters.

The adsorption behavior of inhibitor molecule on metal surface can be assessed by several adsorption isotherms, among which the most commonly used ones, including Temkin isotherm, Langmuir isotherm, and Frumkin isotherm. In order to obtain the isotherm, the surface coverage degree $(\theta)$, which serves as a function of inhibitor concentration, was calculated by corrosion current density values in an attempt to explain the best isotherm. it is 
found in fig . 3 that the adsorption of propolis extract follows Langmuir adsorption .The relationship between $\mathrm{C} / \theta$ and $\mathrm{C}_{\mathrm{inh}}$ at different temperatures $(298,313,353 \mathrm{~K})$ is used to determine the standard free enthalpy energy of adsorption $\Delta \mathrm{G}_{\mathrm{ads}}$ and the constant of adsorption $\mathrm{K}_{\mathrm{ads}}$ using the following equation :

$$
D G_{a d s}=-R T\left(\ln 1000 K_{a d s}\right)
$$

Table 5. Thermodynamic adsorption parameters of copper alloy in ethylene glycol Water (30/70) $0.1 \mathrm{MNaCl}$ in absence and presence of different concentrations of inhibitor

\begin{tabular}{c|cccc}
\hline Température $\left({ }^{\circ} \mathbf{K}\right)$ & $\boldsymbol{K a d s}$ & $\left.\Delta \boldsymbol{G}^{\mathbf{0}} \mathbf{K j} / \mathbf{m o l}\right)$ & $\Delta \boldsymbol{H}_{\text {ads }}^{\mathbf{0}}(\mathbf{j} / \mathbf{m o l})$ & $\Delta \boldsymbol{S}_{\text {ads }}^{\mathbf{0}}(\mathbf{j} / \mathbf{m o l} . \mathbf{K})$ \\
\hline $\mathbf{2 9 8}$ & 0,85763293 & $-16,7460343$ & & \\
$\mathbf{3 1 3}$ & 0,89686099 & $-17,7054257$ & 14452 & 103.8 \\
$\mathbf{3 5 3}$ & 1,98412698 & $-22,3001443$ & & \\
\hline
\end{tabular}

The Negative values of $\Delta \mathrm{G}_{\mathrm{ads}}$ indicates the spontaneity of the adsorption process for temperatures 298 and $313^{\circ} \mathrm{K}$. The $\Delta \mathrm{G}_{\text {ads }}^{0}$ values are lower in $-20 \mathrm{Kj} . \mathrm{mol}^{-1}$. This indicates that the adsorption is physisorption with the existence of electrostatic interaction forces between the molecules and the inhibitory copper surface oxidized spontaneously, whereas a temperature of $353^{\circ} \mathrm{K} \Delta \mathrm{G}_{\text {ads }}$ values are $-22,300 \mathrm{~kJ} / \mathrm{mol}$ which is greater than $-20 \mathrm{~kJ} / \mathrm{mol}$. This indicates that the adsorption corresponds to the chemisorption [7-24].

In order to explain the corrosion inhibition of copper alloy using thermodynamic model, heat of adsorption and entropy of adsorption were determined by the relationship between $\Delta \mathrm{G}_{\mathrm{ads}}$ and temperature:

$$
\Delta G_{a d s}^{0}=\Delta H_{a d s}^{0}-T \Delta S_{a d s}^{0}
$$

The value of $\Delta H_{a d s}^{0}$ is calculated from the intercept and $\Delta S_{a d s}^{0}$ from the slope

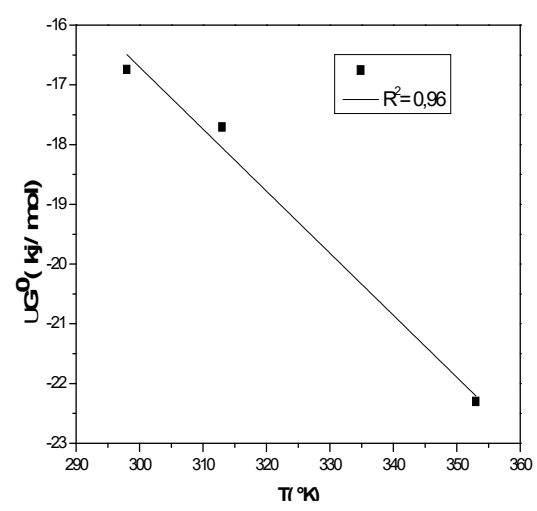

Fig .7. Curve of the variation of the activation energy and the activation enthalpy for the copper alloy in an ethylene glycol / water solution $0,1 \mathrm{M} \mathrm{NaCl}$ at various concentrations of the propolis extract 


\subsubsection{Study of the effect of immersion time by the method of electrochemical impedance}

Effect of various immersion times $(2,4,6$ and $24 \mathrm{~h})$ for the corrosion inhibitor at a concentration of $1.25 \mathrm{~g} / \mathrm{L}$ of propolis extract at $298 \mathrm{~K}$ was studied by the spectroscopy method electrochemical impedance spectroscopy, figure (8) shows the Nyquiste diagrams, bode plot and phase angle after different immersion times containing $1.25 \mathrm{~g} / \mathrm{L}$ of propolis extract at $298 \mathrm{~K}$.
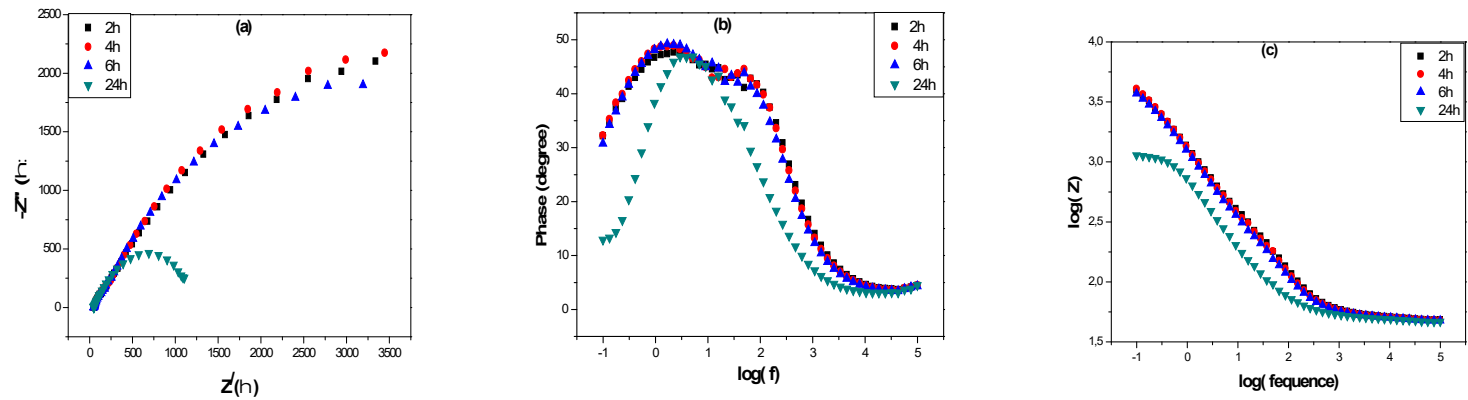

Fig.8. (a) Nyquist plots , (b) Bode (plot) (c) phase angle for copper alloy immersed in an ethylene glycol / water solution $0,1 \mathrm{M} \mathrm{NaCl}$ at different times of immersion

The high frequency containing the straight line of Warburg can be attributed to the diffusion of $\mathrm{Cu}^{2+}$ ion while the low frequency shows the appearance of a half circle. The larger one appears at 2, 4, 6 hours while the smaller one can be attributed to the charge transfer reaction transfer. The smaller one appears after 24 hours of immersion showing the presence of inductive loop which may be attributed to the relaxation process obtained by adsorption species like $\mathrm{Cl}^{-}$and the carboxylic acid derived from the ethylene glycol conversion with the time .a deviation, from perfect circular shape, often known as frequency dispersion, was attributed to surface roughness and in homogeneities of the copper alloy surface [31,32] The bode plot obtained shows the existence of only time constant justified with a straight line slope.

\subsubsection{Observation of the surface by the scanning electron microscopy (SEM)}

The SEM images and EDX composition of the copper alloy surface exposed to ethylene glycol water solution $0.1 \mathrm{M} \mathrm{NaCl}$ in absence and presence of $1.25 \mathrm{~g} / \mathrm{l}$ of propolis extract for 24 $\mathrm{h}$ are presented in fig 9 

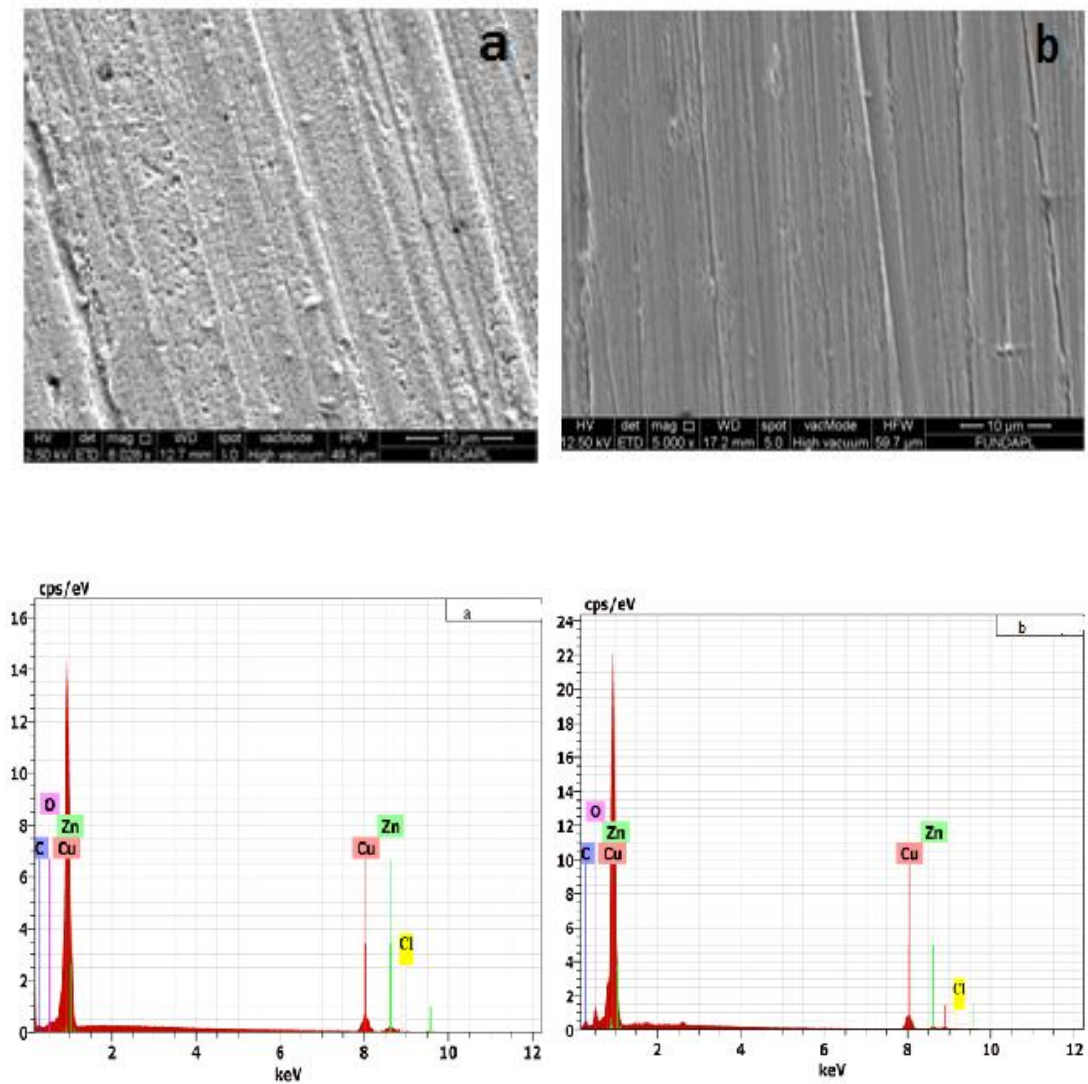

Fig .9. Scaning electron micrographs and EDX spectrum of the copper alloy surface after $24 \mathrm{~h}$ immersion at $298 \mathrm{~K}$ in ethylene glycol water solution (30\%/ 70\%) $0.1 \mathrm{M} \mathrm{NaCl}$ (a) without inhibitor, (b) with inhibitor

The FT - IR spectrum of the solution ethylene glycol -water (30\%/ 70\%) $0.1 \mathrm{M} \mathrm{NaCl}$ containing $1.25 \mathrm{~g} / \mathrm{L}$ propolis extract after and before the immersion the copper alloy surface for $24 \mathrm{~h}$ was analyzed. 


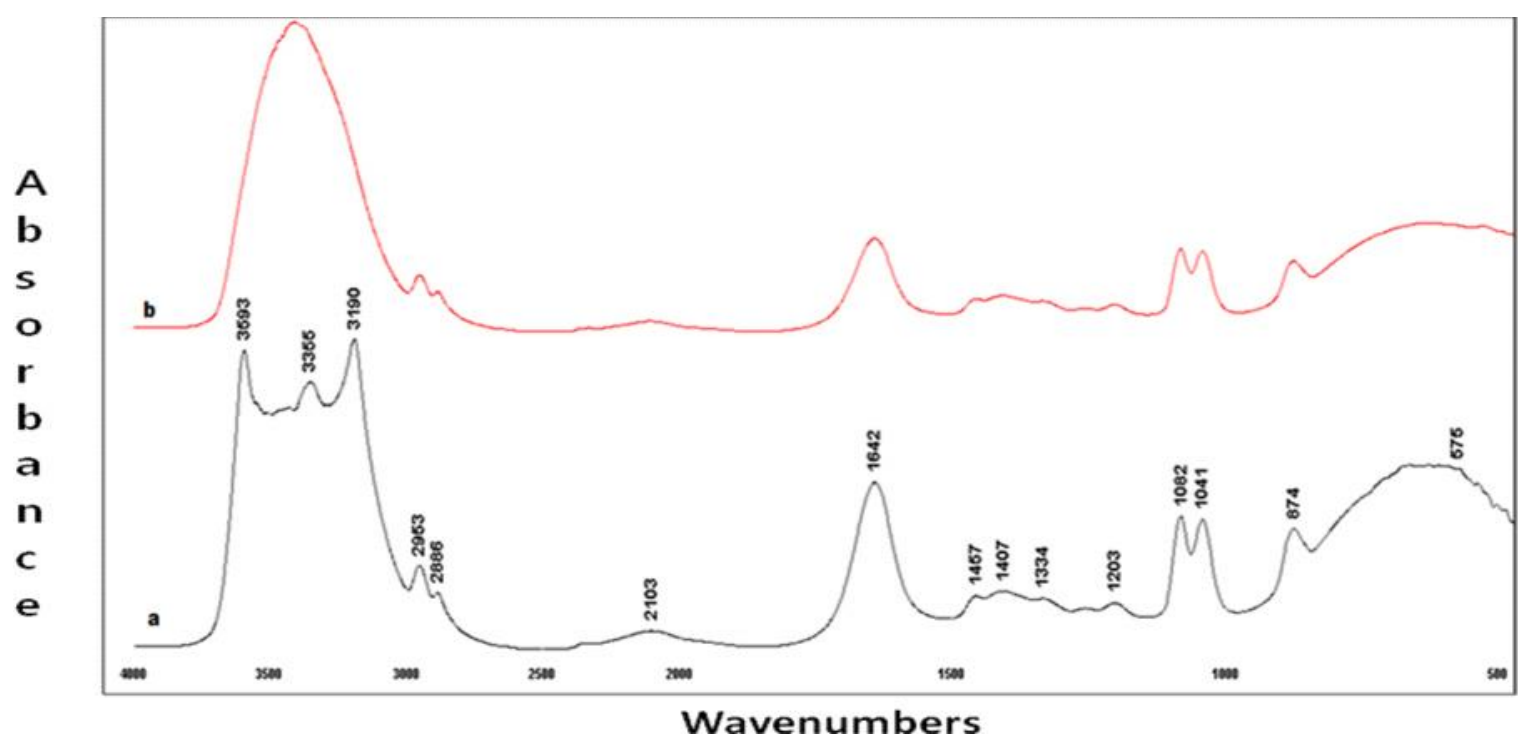

Fig .10. FT - IR Spectrum of the solution ethylene glycol -water $\quad(30 \% / 70 \%) 0.1 \mathrm{M} \mathrm{NaCl}$ containing $1.25 \mathrm{~g} / \mathrm{l}$ prolpolis extract (a) after and (b) before the immersion of the copper alloy surface for $24 \mathrm{~h}$

Figure 10 shows the FT- IR spectrum of propolis extract after immersion. The band at 3593 $\mathrm{cm}^{-1}$ is attributed to $\mathrm{OH}$ free of alcohol and phenol stretching vibration, the bands at 3355 and $3190 \mathrm{~cm}^{-1}$ are due to the $\mathrm{OH}$ associated stretching vibration, the bands at $2953 \mathrm{~cm}^{-1} 2886$ $\mathrm{Cm}^{-1}$ are due to aliphatic $\mathrm{C}-\mathrm{H}(\mathrm{Sp} 3)$ stretching asymmetric and symmetric vibration respectively. The band at $1642 \mathrm{~cm}^{-1}$ is due to the $\mathrm{C}=\mathrm{C}$ aromatic stretching vibration. the band at $1082 \mathrm{Cm}^{-1}$ is due to the stretching vibration $\mathrm{C}-\mathrm{O}$ of the primary alcohol, but $1041 \mathrm{Cm}^{-1}$ is due to the to the stretching vibration $\mathrm{C}-\mathrm{O}$ of ester. The band at $874 \mathrm{Cm}^{-1}$ is attributed to the formation of the bond $\mathrm{C}-\mathrm{Cl}$. Comparison with the spectrum after immersion experiments (fig 10.b) clearly points out to the shift in the frequencies at various functional groups indicating the adsorption of these chemical compounds on copper alloy surface, from the FTIR and SEM - EDX studies. It can be obviously concluded that the various organic compounds containing $\mathrm{OH}, \mathrm{O}, \mathrm{Cl}$, ester and aromatic compound are effectively adsorbed on the copper alloy surface. 


\section{CONCLUSION}

The study of propolis extract as a corrosion inhibitor on the copper alloy in ethylene glycol / water $(30 / 70 \%) \mathrm{NaCl} 0.1 \mathrm{M}$ has allowed us to achieve the following conclusion;

1) The maximum inhibitory efficacy determined by potentiodynamic method is $73.38 \%$ and $55.55 \%$ determined by the impedance technique for concentrating the extract $1.25 \mathrm{~g} / 1$.

2) The plot $\mathrm{C} / \theta$ depending on the concentration of the extract is a straight line of positive slope indicating that the adsorption of this extract obeyed to the Langmuir isotherm.

3) The study of the effect of temperature at different concentrations of the extract of 0.25 to $1.25 \mathrm{~g} / \mathrm{L}$ shows that the molecules of the sample are adsorbed on the alloy surface by electrostatic force low corresponds to physisorption and chimisorption .

3) The effect of duration of treatment shows the increase of the capacitive loop which is a semicircle for a period of immersion of 2, 4 and 6 hours and then decrease one of these for a period of immersion of 24 hours.

\section{ACKNOWLEDGEMENTS}

We would like to express our gratitude to Prof. A. Khelifa, from the Research laboratory of processes Genius, Department of Industrial Chemistry, Faculty of Technology Saâd Dahlab University of Blida for his kind permission to work in his laboratory.

\section{REFERENCES}

[1] Guilminot.E., Rameau.J-J., Dalard, F. Degrigny, C. Hiron. X. Benzotriazole as inhibitor for copper with and without corrosion products in aqueous polyethylene glycol (2000) 21-28.

[2] Fekry. A. M., Fatayerji. M. Z, Electrochemical corrosion behavior of AZ91D alloy in ethylene glycol Electrochemical Acta 54 (2009) 6522-6528.

[3] Niknejad. M, Khomami corrosion of alloy steel in 30\% ethylene glycol solution and $\mathrm{CrO}^{2-}$ under hydrodynamique conditions 20(6) ( 2013 ) 82-87.

[5] Hegazy M. A., Badawi. A. M. Abd El Rehim, S. S, Kamel W. M, Corros. Sci. 69 (2013) $110-122$.

[4] Krishnaveni. K, Ravichandran .J, Fail. J, Anal, and preven 15 (2015) 711-721. 
[6] Nathalie.O, Francis. M, Nadine. P, influence of flow on the synergistic effet of an inhibitive mixture used for water treatment in cooling circuit J Appl. Electrochem 32. (2002) 497.

[7] Noore. A, Journal of Appl Electrochem. 39 (2009) 1465-1475.

[8] Beatriz. C, Mello. S, Miriam .B. Hubinger. D, Inter. J. Food Sci and Techn. 47 (2012) $2510-2518$.

[9] Coral .O, J. Cancer Sci. Ther. 5 (10) (2013) 1948-5956.

[10] Rebiai A., Lanez T., Belfar M. L., Int. J. Pharmacol. 2011, 7 (1), 113-118, doi: 10.3923/ijp.2011.113.118.

[11] Rebiai A., Lanez T., Belfar M.L. Total polyphenol contents, radical scavenging and cyclic voltammetry of Algerian propolis. Int J Pharm Pharm Sci, 2014, 6 (1), 395-400.

[12] Belfar ML., Lanez T., Rebiai A., Ghiaba Z. Evaluation of Antioxidant Capacity of Propolis Collected in Various Areas of Algeria Using Electrochemical Techniques. Int. J. Electrochem. Sci., (2015), 10, 9641 - 9651.

[13] Tsuru .T, Haruyama .S, Gijutsu .B., J. Jpn. Soc. Corros. Eng. 27 (1978) 573.

[14] Ashassi-Sorkhabi .H, Asghari . E, J. Appl. Electrochem. 40 (2010) 631.

[15] MetikosHukovic .M, Baic .R., Grubac .Z, J. Appl. Electrochem. 32 (2002) 35.

[16] Freres .SE,. Stefenel .MM, Mayer. C., Chierchie .T, J. Appl. Electrochem. 20 (1990) 996

[17] Brustein. GT, Cinderey .R, J. Corros. Sci. 32 (1991) 1195.

[18] Cinderey. RJ, Brustein .G.T, Corros. Sci. 33 (1992) 499.

[19] Ladha .D.G. , Wadhwani. P.M., Kumar .S, Shah .N.K , J. Mater. Environ. Sci. 6 (5) (2015) 1200-1209.

[20] Ogundele .G.I., White. W.E., Corros. Sci. 42 (1986) 71.

[21] Wang .D, Xiang. B, Liang. Y, Song .S, Corros. Sci. 85 (2014) 77-86.

[22] Shabani-nooshabadi .M, Sadat Hoseiny .F,Jafari .Y Green Approach to Corrosion Inhibition of Copper by the extract of Calligonum comosum in Strong Acidic Medium Metals \& Materials Society and ASM International (2015), 46-293.

[23] Khadraoui .A, Khelifa.A, Hachama . K, Mehdaoui .R, Thymus algeriensis extract as a new eco-friendly corrosion inhibitor for 2024 aluminium alloy in $1 \mathrm{M} \mathrm{HCl}$ medium Journal of 
Molecular Liquids 12, (2015) 064.

[24] Hachelef. H., Benmoussat. A,. Khelifa. A, Athmani. D, Bouchareb. D, Study of corrosion inhibition by Electrochemical Impedance Spectroscopy method of 5083 aluminum alloy in $1 \mathrm{M} \mathrm{HCl}$ solution containing propolis extract J. Mater. Environ. Sci. 7 (5) (2016)1751-1758.

[25] Assunc.S. S, Pereiraa .A, Pegasa .M.M., Fernandeza .T.L,. Magalhaesa .M, Scho“ntaga T.G., Lagob. D.C, Sennab L.F, E. Corros. Sci. 65 (2012) 360. 529.

[26] Abiolaa .O.K,. Jamesb .A.O, Corros. Sci. 52 (2010) 661.

[27] Bentiss. F., Bouanis. M, Mernari. B, Traisnel .M., Vezin .H., Lagrenee .M., Appl. Surf. 533 Sci. 253 (2007) 3696.

[28] Hoar. T.P, Holliday .R.D, The inhibition by quinolines and thioureas of the acid dissolution of mild steel J. Appl. Chem, 3( 1953) 502-513.

[29] Singh. D.N.N, Chaudhary .R.S,.prakash . B, Agawal .C.V, Corros. J.14 (1979) 2335.

[30] Talati. J. D, Gandhi. D.K. N- hétérocyclic compounds as corrosion inhibition for aluminium- coper alloy in hydrochloric acid, Corros.Sci, 23 (1983) 1315- 1332.

[31] Laidler .K.J, Reaction Kinetics, vol. 1, 1st ed., Pergamon Press, New York, 1963p. 1

[32] Popova .A. Christov. M, Corros. Sci. 48 (2006) 3208.

[33] Lopez. D.A. Simison .S.N, De Sanchez .S.R, Electrochim. Acta 48 (2003) 845.

\section{How to cite this article:}

Hachelef H, Benmoussat A, Khelifa A, and Meziane M. Study of the propolis extract as a corrosion inhibitor of copper alloy in ethylene glycol / water $0.1 \mathrm{~m} \mathrm{NaCl}$. J. Fundam. Appl. Sci., 2016, 9(2), 650-668. 